\title{
Turismo culinario y patrimonio histórico: La ruta de la sal prehispánica en Zapotitlán Salinas, Mexico
}

\author{
Culinary tourism and historical heritage: The route of the prehispanic salt in \\ Zapotitlán Salinas, Mexico
}

\section{Turismo culinário e património histórico: A rota pré-hispânica do sal em Zapotitlán, México}

\author{
Humberto Thomé-Ortiz \\ Universidad Autónoma del Estado de México, México \\ humbertothome@hotmail.com \\ Marie Christine Renard-Hubert \\ Universidad Autónoma Chapingo, México \\ mcrenard@gmail.com \\ Daniel De Jesús Contreras \\ Universidad Autónoma del Estado de México, México \\ djcontreras66@yahoo.com
}

\begin{abstract}
Resumen
Con el objetivo de analizar la relación entre turismo culinario y patrimonio histórico se desarrolló un estudio de caso con enfoque cualitativo, que aborda el análisis de una comunidad productora de una sal milenaria en el centro de México. Las categorías de análisis fueron los actores sociales, el producto alimentario y el territorio. Los resultados muestran que la actividad turística presenta efectos ambivalentes hacia la reproducción social de un bien patrimonial alimentario con fuertes vínculos históricos. Se concluye que es necesaria una revisión de los retos y oportunidades que enfrenta el campo mexicano frente a la inserción del turismo rural como una estrategia de desarrollo.
\end{abstract}

Palabras Clave: turismo culinario; patrimonio histórico; alimentos emblemáticos; desarrollo local.

\begin{abstract}
With the purpose of analysing the relationship between culinary tourism and historical heritage, a case study was developed taking a qualitative approach, which deals with the analysis of a community that produces millenary salt in central Mexico. The categories of analysis were the social actors, the food product and the territory. The results show that the tourist activity presents ambivalent effects towards the social reproduction of the historical-culinary heritage with strong territorial ties. It is concluded that a review of the challenges and opportunities facing the Mexican countryside is necessary, as regards the insertion of rural tourism as a development strategy.
\end{abstract}

Keywords: culinary tourism, historical heritage, emblematic foods, local development.

\section{Resumo}

A fim de analisar a relação entre turismo e património gastronómico, neste artigo apresenta-se um estudo de caso, com abordagem qualitativa, no qual se analisa uma comunidade produtora de sal, milenar, no centro do México. As categorias de análise foram os atores sociais, o produto alimentar e o território. Os resultados mostram que o turismo tem efeitos ambivalentes na reprodução social de um bem patrimonial alimentar com fortes vínculos históricos. Conclui-se que é necessária uma revisão dos desafios e oportunidades que o México enfrenta face à opção do turismo rural como estratégia de desenvolvimento.

Palavras-chave: turismo culinário, património histórico, alimentos icónicos, desenvolvimento local. 


\section{Introducción}

El turismo convencional experimenta importantes transformaciones, derivadas de sus repercusiones económicas, sociales y ambientales, lo que ha motivado que algunos nichos de mercado se orienten hacia el consumo de productos diferenciados. Una de las estrategias de diferenciación es la especialización territorial para generar ventajas comparativas (Aguilar \& Moreno, 2013).

Dentro de las formas de especialización territorial, se encuentran aquellas vinculadas con la producción de alimentos emblemáticos, siendo el turismo culinario una de las modalidades mejor acogidas por los turistas. El desarrollo de este tipo de turismo ha favorecido especialmente al espacio rural, donde la inserción de nuevas actividades supone una herramienta para la generación de ingresos complementarios a las actividades tradicionales (UNWTO, 2012).

De acuerdo con Ellis y Kim (2015), los estudios sobre turismo y alimentos han sido categorizados en dos perspectivas disciplinares: la económica y social. Desde el punto de vista económico, se analiza el papel de los alimentos en la consolidación de destinos turísticos con identidad territorial (Ab Karim \& Chi, 2010; Antun, Goh, Kim \& Yuan, 2009; Cai, Lin \& Pearson 2011). Desde el punto de vista social se analizan las transformaciones que el turismo genera en los alimentos desde el punto de vista de la identidad cultural, en torno a conceptos como autenticidad, mercantilización e invención (Álvarez \& Sammartino, 2009; Avieli, 2013; Gyimóthy \& Mykletun, 2009; Ron \& Timothy, 2013).

Sobre la intersección entre turismo, historia y alimentos, se identifican estudios que abordan los casos de México y Suecia (Renard \& Thomé-Ortiz, 2010; Renard \& Thomé-Ortiz, 2016; Rytkönen, 2016; Rytkönen, Bonow, Johansson \& Persson, 2013; Thomé-Ortiz, Renard, Nava \& De Souza, 2014). Dichos trabajos se centran en el análisis de los productos agroalimentarios que motivan los desplazamientos turísticos, con énfasis en las transformaciones de los sistemas productivos y la relación entre tradición y modernidad. Sin embargo, estos trabajos han soslayado el estudio de las dinámicas territoriales que implica la puesta en valor del patrimonio histórico-culinario, a través del turismo.

La zona de estudio es Zapotitlán Salinas, Puebla, una comunidad rural del centro de México especializada en la producción de sal mediterránea, obtenida mediante procesos de evaporación en piletas de piedra, a partir del agua salada, extraída de pozos superficiales, producto de tiempos en que estas tierras eran mares jurásicos y cretácicos.

El suelo de Zapotitlán presenta una acumulación de carbonato de calcio con capas de humus de mínimo espesor, por lo que el desarrollo de la agricultura es limitado y, desde la antigüedad, ha requerido de sistemas de riego en canales de piedra. La precaria calidad del suelo en conjunto con un clima semidesértico, hacen que las opciones productivas sean muy pocas. La pobreza y la falta de oportunidades empujan, a su población masculina, a migrar hacia Estados Unidos. Se estima que en los últimos veinte años ha emigrado más del $50 \%$ (SEDESOL, 2008).

Los registros sobre la ocupación humana en Zapotitlán datan del Período Formativo (200 a.C.); existen en la comunidad muestras de arquitectura monumental que abarcan hasta el siglo XIV, lo que se traduce en una ocupación de quince siglos (Castellón, 2006; 2007). En diversos periodos de la historia, Zapotitlán fue un lugar estratégico desde el punto de vista económico y político, lo que se asocia con la presencia de sal y piedras calcáreas, además de ser una región de tránsito entre las rutas de intercambio comercial hacia el Golfo, Oaxaca y el mundo maya (Gámiz, 1999). 
La sal prehispánica es un producto con anclaje territorial, vinculado con factores históricos y culturales; además de una reputación ganada por sus atributos macroscópicos y organolépticos, a través de sus usos culinarios, pero paradójicamente, no ha logrado posicionarse en el mercado ya que su precio no es redituable respecto a sus costos de producción y el trabajo invertido. La falta de la justa retribución económica de este producto ha sido un factor decisivo en el abandono gradual de las salinas en favor de otras actividades más rentables.

En este contexto se registran dos tendencias importantes: el envejecimiento de los salineros, con la consecuente pérdida de sus saberes y su patrimonio tangible; y formas rudimentarias de industrialización de la sal, de menor calidad, destinada al ganado y más redituable, lo cual, de generalizarse, amenazaría la existencia de la sal gastronómica. Estos dos aspectos, han influido en la búsqueda de otras alternativas que ayuden a la reproducción socioeconómica de este patrimonio.

En últimos años surgieron iniciativas como la implementación de una ruta turística alrededor de la sal o la diversificación cosmética, culinaria y terapéutica del producto, a través de nuevas preparaciones que hacen pensar en una revitalización de su importancia para la economía local; donde nuevos actores entran en juego, entre los que destaca el papel de los grupos organizados de mujeres y de migrantes retornados de los Estados Unidos, que invierten su capital económico, cultural y social en actividades turísticas que, de manera indirecta, están interviniendo en la preservación y rehabilitación de las salinas.

El texto se divide en cinco partes. Seguido de este apartado introductorio, se realiza un recorrido histórico a través de la sal prehispánica de Zapotitlán y sus implicaciones como recurso patrimonial. En tercer lugar, se presenta el diseño metodológico del caso estudiado. Más adelante, se construye un balance de los aspectos positivos y negativos de la relación entre sal y turismo. Finalmente, el texto concluye con una reflexión acerca de las ambivalencias que presenta el turismo frente al patrimonio histórico-culinario.

\section{La sal prehispánica de Zapotitlán: un recurso histórico}

Esta sal es un producto alimentario con una profundidad histórica cercana a 2000 años y cuya permanencia está asociada con el hecho de que la sal constituye un recurso constante para la comunidad al que, a lo largo del tiempo, se ha acudido como una fuente de ingresos. Su producción se remonta a épocas prehispánicas cuando la etnia popoloca, la tributaba a los aztecas y en la época colonial estuvo asociada con la industria minera.

La producción de sal ha representado, una forma de capital intercambiable para quienes la poseen, pues siempre se recurre a ella cuando se presentan tiempos difíciles. Las salinas, nombre que se da a las pilas de evaporación, son una fuente de empleo, producen un bien alimentario para autoconsumo, pueden rentarse a otros, pueden darse a "medias" para que alguien más las trabaje, a cambio de la mitad de la producción, o en los casos más extremos, pueden venderse.

La producción de esta sal supone el desarrollo de una habilidad productiva y comercial, que ha permitido la reproducción social de una comunidad, cuyo ambiente no es favorable para otro tipo de actividades. Según Castellón (2006), los restos arqueológicos de Zapotitlán demuestran que este lugar fue el centro político de la cultura popoloca, debido a la existencia de las salinas. Al respecto existen contradicciones sobre la existencia de estas infraestructuras: de acuerdo con Williams (2003), las salinas se remontan a épocas prehispánicas, mientras que 
la presencia de montículos formados por pedazos de cerámica se asocia con la producción de "panes" de sal elaborados por combustión y más fáciles de transportar. Esta segunda versión, se confirma por Castellón (2007), según quién en aquellos tiempos, la sal se obtenía por lixiviación de tierras saladas y combustión artificial de las salmueras hervidas en recipientes de barro. De acuerdo con ese mismo autor, fue después de la conquista española, hacía 1525 , cuando se adoptó el sistema de evaporación solar en estanques, el cual tendría entonces una antigüedad cercana a los 500 años.

Durante la época colonial, la sal experimentó un incremento en su importancia comercial, pues era un insumo indispensable para la explotación de las minas de plata. Por ser un elemento clave para la minería, la corona española expide en 1580, reglamentos que prohíben a españoles, mulatos y mestizos habitar lugares donde se explotaba sal; la prohibición de sacar indios de los pueblos salineros; la obligatoriedad para que los indios mantuvieran limpios los ojos de agua salados de su propiedad y las salinas; igualmente, había severos castigos para aquellos que adulteraran la sal (Sepúlveda, 2006).

La importancia del producto sufrió un declive durante el siglo XIX, cuando la minería adoptó el método de cianurización y prescindió de la sal como un insumo determinante. A pesar de ello, la sal continuó produciéndose de forma tradicional pues seguía presente en los mercados debido a sus funciones en la ganadería, la cocina y la medicina tradicional.

\subsection{La producción artesanal de sal, una herencia productiva}

La historia natural de Zapotitlán incidió en el desarrollo de la producción de sal, pues las condiciones del entorno siempre fueron un escenario adverso para el desarrollo de otras actividades productivas. Desde tiempos remotos la producción y comercialización de sal fue una actividad económica preponderante. Al tratarse de una sal mediterránea, se vinculó a las tierras y a los ríos salados de donde proviene. El florecimiento de estas explotaciones salineras se debió al aprovechamiento de los fenómenos de concentración, saturación, y evaporación, así como al aprovechamiento creativo de lluvias, aire, clima y disponibilidad de agua salada (Castellón, 2006).

La explotación salinera tiene un anclaje sociocultural asociado con el uso de herramientas especializadas, procedimientos corporales y rituales específicos. El sistema de producción es de tipo artesanal, transmitido de generación en generación y se distingue claramente de la lógica comercial de las refinerías industriales. Sus métodos autóctonos son resultado de la experiencia empírica que incluye dimensiones como la vida cotidiana, las costumbres y las creencias.

La producción de esta sal no ha variado considerablemente desde hace cinco siglos. Entre los cambios registrados se encuentran: la implementación de bombas de gasolina y mangueras de hule para extraer el agua salada de los pozos, en sustitución del trabajo manual; hasta hace unos cincuenta años, se bajaba a los pozos por escaleras de piedra y se cargaba el agua en cántaros de barro. Los trabajadores que realizaban esta tarea eran pagados por cada cien cargas de agua, por lo que se llamaban “cienteros" (Castellón, 2007). Tradicionalmente, los estanques de unos $10 \mathrm{~cm}$ de profundidad donde se deja el agua salina para su evaporación se construían formando terrazas con piso de piedra recubierta con cal; esta "cal de horno", fabricada mediante la quema de piedras calizas, ha sido prohibida dado el alto consumo de combustible vegetal empleado para su elaboración y ha sido reemplazada por cemento. El cemento no cambia el sabor de la sal, pero es más caliente y el proceso de evaporación resulta 
más rápido. Sin embargo, los salineros refieren que mientras las salinas de cal podían durar hasta cien años, las salinas de cemento se deterioran en diez años.

La producción de esta sal es de tipo artesanal, basado en el trabajo y la observación del salinero. El proceso comienza dos semanas después de haber iniciado el reposo de las aguas saladas; transcurrido ese tiempo, se lavan las pilas para eliminar los sedimentos terrosos que se van depositando al fondo de las mismas. Limpiar implica trasvasar el agua de una pila o salina a otra, mediante una labor manual en posición de inclinación; este trabajo requiere un esfuerzo meticuloso para conseguir una salmuera limpia. Una vez trasvasado el líquido, se procede a una detallada limpieza de la pila inicial, con fibras de ixtle, que algunos salineros han sustituido por fibras sintéticas. Ya limpia la pila, se regresa el agua colada de la segunda pila, o pila de decantación. La efectividad del proceso se comprueba a través del aspecto del agua que pasa de uno turbio a otro más cristalino. Posteriormente, toma lugar el proceso de solidificación que se manifiesta en poco tiempo, al formarse una capa de cristales salinos en la superficie del agua. Al siguiente paso, se le llama "bajar la sal”, que consiste en desprender los cristales de la superficie, agregándoles agua, con la intención de que se dirijan al fondo y así acelerar el proceso de cristalización de los líquidos.

Después de seis semanas de iniciado el proceso, puede hacerse un primer ciclo de recolección de una sal, llamada "tierna", destinada al consumo humano. Esta sal, aún con mucha humedad, se coloca en canastos de mimbre, que cumplen la función de escurridores para secarla unos días y posteriormente almacenarla en cuevas labradas por los salineros, para así protegerla de la humedad que afecta su calidad. Actualmente quedan pocas de estas cuevas tradicionales y están siendo sustituidas por cuartos de adobe o cemento.

Después de la primera recolección, hay aún bastante agua en las salinas para un segundo ciclo. El producto de este ciclo será una sal más gruesa, opaca y de sabor amargo que se destina al ganado. Los meses de marzo, abril y mayo son los meses de cosecha. En esos meses de sequía, el trabajo es diario, 7 días a la semana, 8 horas al día.

La concentración estacional de la actividad provoca mayor demanda de mano de obra en un tiempo corto; tradicionalmente, los dueños de las salinas recurrían a jornaleros provenientes de otras comunidades de la región. El conocimiento y el saber-hacer, para determinar, cuando la sal está a punto, lo detentan los "maestros", ancianos que dirigen a jóvenes salineros que no poseen estos saberes.

\section{Metodología}

El objetivo general del presente trabajo es identificar las relaciones entre turismo culinario y patrimonio histórico, a partir del aprovechamiento de los alimentos ancestrales como recursos turísticos. Para el cumplimiento de este objetivo se plantearon tres objetivos particulares: i) Analizar la sal prehispánica de Zapotitlán como un recurso histórico de importancia socioeconómica; ii) Comprender la interpretación de la sal como un recurso turístico con anclaje territorial; y iii) Caracterizar los procesos de apropiación del patrimonio históricoculinario como recurso turístico.

Para ello se desarrolló un estudio de caso (Stake, 2000) de tipo cualitativo, durante el periodo comprendido entre 2009 y 2015. A partir de entrevistas a profundidad aplicadas a 12 informantes, determinados mediante un muestreo no probabilístico de bola de nieve (Noy, 2008), en el que se seleccionaron personas con las siguientes características: i) que fueran propietarios de las salinas por más de tres generaciones; ii) que actualmente desarrollaran el 
oficio de salinero; y iii) que la sal fuera su principal medio de subsistencia. La información recabada en las entrevistas fue sistematizada mediante un análisis de contenido para después ser codificada (Hsieh \& Shannon, 2005; Piñuel, 2002). También se empleó el método etnográfico, a través de técnicas como la observación participante (Ameigeiras, 2006). Con la finalidad de resguardar la identidad de los informantes, sus nombres fueron cambiados.

Se aplicaron 12 entrevistas semiestructuradas de 45 preguntas, organizadas en tres secciones. i) la primera referida a la multifuncionalidad del territorio, ii) la segunda referente a la coexistencia de actividades nuevas y tradicionales y iii) la última sobre las relaciones de conflicto alrededor del uso y aprovechamiento de la sal (Hoefle, 2016).

De acuerdo con lo anterior, la categoría analítica de la multifuncionalidad (Reig, 2002) es el elemento central que permite el análisis crítico de los límites y oportunidades que presenta el aprovechamiento turístico del patrimonio histórico- culinario.

Para abordar la lógica de multifuncionalidad se analizaron los datos que reflejan los múltiples usos del territorio salinero, asociados con aspectos productivos, ecológicos y recreativos. La lógica de coexistencia se centró en la búsqueda de la superposición de distintos actores locales, con distintos propósitos, pero convergentes en unidades de tiempo y espacio. Mientras que la lógica de conflicto se basa en el análisis de las tensiones sociales emergentes, alrededor del acceso y aprovechamiento de la sal.

\section{Apropiación turística del patrimonio histórico-culinario}

\subsection{Los propietarios del patrimonio}

La actual distribución de propietarios de las salinas tiene origen en el siglo XIX. Anteriormente, las tierras pertenecían a los caciques Pacheco, recibidas quince generaciones atrás del tlatoani mexica Moctezuma II. En 1850, el último de estos caciques, Hermenegildo Pacheco, vendió las tierras que incluían las salinas a habitantes del pueblo, que tuvieron los recursos para pagarlas. En 1875, se otorgó al pueblo el rango de Villa de Zapotitlán. Durante este periodo, se experimentó un aumento en la producción de sal, que produjo un auge económico que culminaría con la Revolución Mexicana.

La propiedad de las salinas estuvo en manos de los miembros de aquella sociedad agrícola establecida por quienes compraron las tierras al cacique. Posteriormente, han existido diversos procesos de herencia y/o venta hasta llegar a su configuración actual. A ello hay que agregar que la sucesión de las salinas, normalmente incluye varios herederos con lo que se presenta un proceso de fragmentación del sistema productivo.

Cabe destacar que las salinas están situadas en tierras comunales, lo que supone que sus propietarios no cuentan con documentos legales que amparen su propiedad, ante lo cual el reconocimiento social sobre quien es el dueño de cada salina es suficiente. Cuando una salina es vendida, lo que se vende no es la tierra ni la infraestructura, sino el derecho a trabajar, siendo una posibilidad reservada únicamente para los miembros de la comunidad. En total, son 117 los dueños para todas las salinas (Thomé-Ortiz, 2012).

Las salinas constituyen un patrimonio histórico para todo el pueblo. Sin embargo, la concentración de las mismas en manos de unas cuantas familias explica que exista cierta apatía por parte del resto de los pobladores para su preservación y la falta de una estrategia colectiva para su puesta en valor.

\subsection{De los propietarios particulares a un producto con anclaje territorial}


La sal prehispánica de Zapotitlán es un producto reconocido por sus cualidades y muy valorado en la gastronomía local, es comercializado en los mercados cercanos directamente por salineros. Su reconocimiento, se extendió gradualmente hacia la región de la Mixteca, donde la llevaban mercaderes ambulantes. Es un elemento esencial para la preparación del famoso mole de caderas y de la fiesta de la matanza de chivos que se realiza en el mes de octubre. ${ }^{1}$ También es indispensable para la preparación de platillos locales a base de cactáceas como las tetechas, los palmitos, las cacallas, e insectos como el gusano cuchamá, que están siendo revalorizados en restaurantes del pueblo, a partir del turismo.

Por otra parte, los métodos de producción tradicional de sal generan una demanda de productos de las comunidades vecinas como canastos, ollas de barro, ixtle y maguey, utilizados en el proceso productivo y que determinan dinámicas de complementariedad entre las actividades productivas.

La "cultura salinera" de Zapotitlán se manifiesta en la celebración de fiestas populares cuya función es la creación de un lazo social entre los integrantes de esta comunidad: para la Santa Cruz, en mayo, los salineros acostumbran realizar una fiesta en las salinas. Ese día, se celebra una misa y los salineros y sus familias comparten una comida. Esta tradición descansa en los productores más ancianos, por lo que podría desaparecer junto con ellos, como ha ocurrido ya en la zona de las salinas Chiquitas donde ningún dueño ha retomado su organización después de fallecido el anciano que se hacía cargo; pero sigue vigente en otros sitios de salinas (Thomé-Ortiz, 2012).

La vida religiosa de Zapotitlán Salinas estuvo ligada a la producción de sal, cuando parte de las ganancias obtenidas de su venta se dedicaba al gasto de la fiesta de San Martin de Tours. De acuerdo con los informantes entrevistados, esta costumbre perduró hasta los años setenta pero, posteriormente, por la disminución de las cosechas, "se olvidaron de los santos" y dejaron de tributar para las fiestas (Renard \& Thomé-Ortiz, 2016).

La inserción del turismo en el sistema de producción de sal pone de manifiesto la emergencia de una lógica de multifuncionalidad, puesto que al transformar las salinas en escenarios para el ocio recreativo de los urbanitas el espacio adquiere nuevas funciones y significados; ello también plantea la coexistencia entre actores locales que con distintos propósitos se aproximan a la sal como un recurso capaz de generar ingresos en muy diversos sentidos. Es clara la emergencia de nuevos conflictos por los recursos locales, pues la introducción del turismo trajo consigo ciertas tensiones entre los actores sociales.

\subsection{De patrimonio histórico a recurso turístico: implicaciones socioculturales de la valorización recreativa de la sal}

La profundidad histórica de la sal fue uno de los principales puntos de partida para la conceptualización de una ruta turística. Inicialmente, la estrategia obedeció a la premisa de generar opciones de diversificación productiva para la población de Zapotitlán como mecanismo de valorización de los recursos locales y una estrategia de desarrollo local (Montanari \& Staniscia, 2009; Costello \& Smith, 2009; Voth, 2010). Justamente, la

\footnotetext{
${ }^{1}$ Desde la época colonial, se sigue celebrando, en el mes de octubre, en Tehuacán, la "matanza de chivos", animales cebados durante once meses antes de su sacrificio. En las semanas anteriores a la matanza, reciben como único alimento la sal de Zapotitlán Salinas que les confiere un sabor único. La matanza de chivos se ha vuelto un magno evento turístico.
} 
multifuncionalidad del territorio fue el elemento clave para la inserción del turismo culinario, ya que los actores locales vislumbraron nuevas posibilidades productivas más allá de las que tradicionalmente venían desarrollando. Lo anterior es el caso de Miguel, joven de 23 años que trabaja como guía dentro de la ruta. Miguel estudia entre semana y desarrolla otros oficios. Los ingresos que obtiene como guía los emplea para cubrir sus estudios, manutención y entretenimiento, por lo que ve favorablemente el proyecto de ruta.

La actividad turística en Zapotitlán, implicó la movilización de actores internos y externos (Brunori \& Rossi, 2000) para poder generar la ruta. Para ello fue necesaria la vinculación entre la comunidad, organizaciones no gubernamentales e instituciones públicas. Pese a que en el territorio ya existían antecedentes de actividades ecoturísticas, la idea de vincular el turismo con la sal surge de un grupo de mujeres, financiado por la Red Nacional de Mujeres Rurales (RENAMUR) y con el asesoramiento de la consultora Tierra y Turismo.

Como se puede observar la vinculación entre turismo y patrimonio histórico-culinario es producto del desarrollo de redes entre actores locales y agentes externos, a través de las cuales se generó un fortalecimiento del capital social y cultural de la comunidad, para el desarrollo de una nueva actividad productiva. En este caso, la organización de las mujeres, derivada de la marcada migración masculina hacia los Estados Unidos, fue fundamental para la consolidación de la idea del proyecto, pues este grupo contaba con un trabajo colectivo previo y las relaciones necesarias con el exterior para gestionar la conformación de una iniciativa de turismo culinario.

La implementación de la ruta significaba una forma de apropiación de la profundidad histórica de la sal, que aparentemente pertenecía a la colectividad y era necesaria para ofertar un producto turístico altamente diferenciado. Se trataba del producto más emblemático del territorio y un fuerte marcador de identidad territorial, lo cual le imprimía un sello de exclusividad como propuesta de turismo culinario (Gyimóthy \& Mykletun, 2009; Ellis \& Kim 2015). Ello buscaba responder a una demanda turística crecientemente diferenciada (Ron \& Timothy, 2013).

La profundidad histórica de la sal representaba su principal argumento de autenticidad a los ojos del consumidor contemporáneo (Espeitx, 2011). Sin embargo, su tránsito de patrimonio histórico a recurso turístico, ha conllevado implícita una reinterpretación sociocultural de sus sentidos; como alimento, como bien cultural y como recurso económico; es decir, se observa una multiplicidad de usos y significados, que ha incrementado los conflictos sociales alrededor del recurso.

Ello es el resultado de que el aprovechamiento turístico de la sal no respondió a una legítima acción colectiva sino a los intereses de un grupo: el de las mujeres organizadas, sin implicar seriamente a los salineros y otros actores locales. El proceso de activación patrimonial de la sal se basó en la imagen del producto, con ausencia de sus depositarios, lo que no necesariamente respondía a las expectativas de la comunidad. El turismo fue concebido desde una visión ajena a la producción de sal y convertida en un producto orientado al mercado turístico. Lo cual abre un cuestionamiento amplio sobre la pregonada multifuncionalidad de los espacios rurales que, como aquí se observa, no está exenta de generar tensiones entre los actores sociales y su relación con el espacio y los recursos.

Debido al esfuerzo físico requerido, la producción de sal fue una actividad desempeñada por hombres, mientras que el papel de la mujer era marginal. La producción de sal se había mantenido como una actividad exclusivamente masculina, aspecto que se transforma con la introducción del turismo. Si bien en la actualidad la producción de sal sigue siendo un dominio 
masculino, con el desarrollo de la ruta, el turismo ha recaído en el género femenino. Lo anterior, describe dos niveles de apropiación del mismo patrimonio histórico. La apropiación material encabezada por el género masculino y la apropiación del capital simbólico hecha por las mujeres a partir del turismo.

Con la ruta de la sal hemos podido hacer nuevos negocios, tenemos hoteles, preparamos sales terapéuticas, cremas y ahora tenemos el spa. (Martha, 39 años)

Ello significa que el grupo de mujeres se ha beneficiado más de los significados de la sal que del producto en sí mismo; lo que significa que el turismo es una herramienta que moviliza sentidos, a partir del valor histórico de la sal. Así, la apropiación del patrimonio históricoculinario se da en un plano discursivo, recreado por la acción conjunta de anfitriones y visitantes (Álvarez \& Sammartino, 2009; Brouder \& De la Barre, 2013; Belhassen, Hillel \& Shani, 2013). La memoria histórica fue determinante en la valorización (Andreu \& Pujadas, 2011) de la sal. Aquí es posible observar que la preconcebida multifuncionalidad, no es un hecho en sí, sino que depende del consenso entre los actores locales al generar procesos de territorialización, basados en la sinergia y el beneficio mutuo.

Los desacuerdos entre el grupo de mujeres y los salineros no se hicieron esperar, pues el valor simbólico de la sal, así como sus recursos materiales, ofertados al turismo, se convirtieron pronto en un campo de disputa entre ambos grupos. Los salineros argumentan no recibir ningún beneficio concreto de la actividad turística, pero si experimentar la presión de los visitantes sobre su zona de trabajo, aspecto que refleja el potencial conflicto generado por una multifuncionalidad forzada del territorio.

En temporada de cosecha (de la sal) los turistas muchas veces nos estorban y nosotros no le vemos ningún beneficio al turismo. (Juan, 58 años)

Ciertamente, el turismo representa una oportunidad de poner en valor la sal, a partir de la recuperación de la identidad local, pero para ello es necesario que el desarrollo del turismo tenga un carácter incluyente (Renard \& Thomé-Ortiz, 2010). Al respecto, existe un antecedente de revalorización de unas salinas en Europa² que fue posible por los vínculos históricos de un grupo social con el territorio (Muchnik, 2012).

Por otra parte, la inserción de la actividad turística motivó el interés de otros actores por participar en la ruta. Tal es el caso del grupo de migrantes retornados de Estados Unidos, quienes aportaron capital cultural y económico para la consolidación del proyecto. El caso de Antonio sirve para ilustrar esta situación. Antonio es un migrante que trabajó mucho tiempo como cocinero en restaurantes de Nueva York, a su retorno al pueblo y con los ahorros acumulados, abrió un pequeño restaurante en el que ofrece platos tradicionales y fusiones con platos internacionales. Otro ejemplo es el de Pedro, que al igual que Antonio, es un migrante retornado que invirtió sus ahorros en la apertura de un hotel modesto y una pizzería.

La contribución de estos actores ha creado nuevos esquemas de apropiación turística de la sal, basados en su mayor disponibilidad de recursos económicos, conocimientos y habilidades respecto a otros actores que no han tenido la experiencia de vivir en otro país. Los

${ }^{2}$ http://www.leguerandais.fr/ 
migrantes repatriados han creado redes sociales para iniciar nuevos negocios, siendo la ruta un destino para la inversión del capital económico que adquirieron en los Estados Unidos.

La emergencia de nuevos actores y nuevas actividades ha acentuado los conflictos en torno a la apropiación de los recursos locales y los beneficios que estos producen. El grupo de mujeres es quien ostenta un mayor capital político y poseen la marca de la ruta, con lo que suelen favorecer a los negocios de su grupo. Por otra parte, los salineros, quienes no fueron contemplados en el desarrollo del proyecto, suelen oponerse al turismo e impedir el acceso de los visitantes, por considerar que no obtienen beneficios del proyecto. Mientras que el grupo de migrantes cuenta con recursos económicos y conocimientos que les permiten insertarse con mayor éxito en el negocio turístico. Estas ambivalencias permiten observar las fracturas sociales generadas por el turismo y evidencian diferentes niveles de apropiación del patrimonio histórico-culinario con base en las asimetrías socioeconómicas de la propia estructura social.

\section{Conclusiones}

La sal prehispánica de Zapotitlán es un recurso alimentario de gran profundidad histórica, hasta hace poco su producción representaba una opción productiva para aquellos quienes poseen salinas, mientras para los otros actores sociales solo era parte de su identidad territorial. Lo anterior significaba que el aprovechamiento de este producto estaba cerrado a un grupo pequeño de productores, pero que representa parte de la identidad cultural de toda la comunidad. Con la emergencia de otros actores sociales que incursiona en la tradición salinera, pero desde una postura aparentemente más indirecta, en actividades como el turismo o las artesanías, se pone de relieve la existencia de una lógica de conflicto. Aspectos como la evidente diferencia de posesión de capitales económico, social, político y cultural; la asimetría en la apropiación de recursos materiales e inmateriales; la desigual participación en los proyectos y la inequitativa distribución de los beneficios, favorecen la aparición de fracturas en las relaciones de la comunidad y ponen en duda el logro de los objetivos de desarrollo local que tendría una iniciativa turística.

La sal es un producto que enfrenta serios problemas para ser valorado y que su rentabilidad es muy reducida en un ambiente altamente competitivo. Por ello la búsqueda de opciones para agregarle valor, como el turismo, son importantes para la generación de bienestar económico y para la reproducción sociocultural de este baluarte alimentario. Justamente esta condición revela el carácter multifuncional del territorio salinero, porque mientras su producción y comercialización con propósitos específicos es escasamente redituable, otras opciones productivas amplían el margen de posibilidades para valorizar a un producto que encuentra su máxima fortaleza en sus singularidades, las cuales, a su vez, están directamente vinculadas con su carácter endógeno y su profundidad histórica. En el mismo sentido, la multifuncionalidad propone la posibilidad de que los pequeños productores incursionen en otras actividades, y con ello se reduzca una posible dependencia socioeconómica, aunque también puede prestarse para la fragmentación de la tradición productiva, del producto y del territorio, suscitando diversas formas de apropiación, como las señaladas en apartados anteriores.

Asimismo, la conversión de un alimento con profundidad histórica en recurso turístico, plantea un importante desafío para la sal y sus depositarios, el cual está relacionado con la posibilidad latente de su mercantilización irrestricta para satisfacer deseos de turistas motivados por el consumo de productos diferenciados (Avieli, 2013; Chhabra, Lee, Scott \& 
Zhao, 2013). En la perspectiva del presente trabajo, esta transición es la que explica la lógica de coexistencia, porque sin dejar de cumplir su cometido como patrimonio cultural para los zapotitecos, la sal puede tener muchos sentidos en su dimensión mercantil y como recurso económico. Si bien desde antaño esta última había estado presente, sólo recientemente ha incrementado su importancia pecuniaria, sobre todo en un territorio donde las actividades productivas no son muy abundantes, por lo que en determinado momento podría llegar a sobreponerse a los otros valores no monetarios, de ahí el riesgo de su probable cosificación.

\section{Referencias bibliográficas}

Ab Karim, S. \& Chi, C. (2010). Culinary tourism as a destination attraction: An empirical examination of destinations' food image. Journal of Hospitality Marketing \& Management, 19 (6), 531-555. doi: $10.1080 / 19368623.2010 .493064$

Aguilar, E. \& López, I. (2013). La nueva economía rural europea. Especialización territorial de calidad en la Isla de Texel y la Sierra de Cádiz. Gazeta de Antropología, 29 (2), 1-19.

Álvarez, M. \& Sammartino, G. (2009). Empanadas, tamales y carpaccio de llama. Patrimonio alimentario y turismo en la Quebrada de Humahuaca-Argentina. Estudios y Perspectivas en Turismo, 18 (2), 161175 .

Ameigeiras, A. (2006). El abordaje etnográfico en la investigación social. In I. Vasilachis (Ed.), Estrategias de investigación cualitativa (pp. 107-75). Barcelona: Gedisa.

Andreu, A. \& Pujadas, J. (2011). El turismo de memoria: La patrimonialización de la memoria histórica en Catalunya. El proyecto “más allá de una batalla” (La batalla del Ebro, Gandesa). In A. Santana \& L. Prats (Eds.) Turismo y patrimonio, entramados narrativos (pp.271-288). España: Pasos.

Antun, J., Goh, B., Kim, Y. \& Yuan, J. (2009). Web marketing in food tourism: A content analysis of web sites in west Texas. Journal of Culinary Sciences and Technology, 7 (1), 52-64. doi: $10.1080 / 15428050902788352$

Avieli, N. (2013). What is local food? Dynamic culinary heritage in the World Heritage Site of Hoi An, Vietnam. Journal of Heritage Tourism, 2-3 (8), 120-132. doi: 10.1080/1743873X.2013.767812

Belhassen, Y., Hillel, D. \& Shani, A. (2013). What makes a gastronomic destination attractive? Evidence from the Israeli Negev. Tourism Management, 36 (1), 200-209. doi: 10.1016/j.tourman.2012.12.006

Brouder, P. \& De La Barre, S. (2013). Consuming stories: Placing food in the arctic tourism experience. Journal of Heritage Tourism, 8 (2-3), 213-223. doi: 10.1080/1743873X.2013.767811

Brunori, G. \& Rossi, A. (2000). Synergy and coherence through collective action: Some insights from wine routes in Tuscany. Sociologia Ruralis, 10 (40), 409-423. doi: 10.1111/1467-9523.00157/full

Cai, L. A., Lin, Y. \& Pearson, T. E. (2011). Food as a form of destination identity: A tourism destination brand perspective. Tourism and Hospitality Research, 11(1), 30-48. doi: 10.1057/thr.2010.22

Castellón, B. (2006). Cuthá: El Cerro de la Máscara. Arqueología y etnicidad en el Sur de Puebla. México: INAH.

Castellón, B. (2007). Un grano de sal: Aportaciones etnoarqueológicas al estudio histórico de una industria ancestral. Anuario de Historia, 1, 67-83.

Chhabra, D., Lee, W., Scott, K. \& Zhao, S. (2013). Marketing of ethnic food experiences: Authentication analysis of Indian cuisine abroad. Journal of Heritage Tourism, 2-3 (8), 145-157. doi: $10.1080 / 1743873$ X.2013.767816

Costello, C. \& Smith, S. (2009). Culinary tourism: Satisfaction with a culinary event utilizing importanceperformance grid analysis. Journal of Vacation Marketing, 15 (2), 99-110. doi: $10.1177 / 1356766708100818$

Ellis, A. \& Kim, S. (2015). Noodle production and consumption: From agriculture to food tourism in Japan. Tourism Geographies, 1 (17), 151-167. doi: 10.1080/14616688.2014.978812

Espeitx, E. (2011). Productos de la tierra y alimentos transgénicos: Tradición e innovación como atributos valorados y como factores de riesgo. In E. Espeitx \& J. Cacéres (Eds.) Sabores culturales, ensayos sobre alimentación y cultura (pp. 118-158). España: Montesinos.

Gámiz M. del. S. (1999). Los pueblos popoloca de Tecamachalco - Quecholac. Historia, sociedad y cultura de un señorío prehispánico. (Tese de doutoramento não publicada). ENAH, México. 
Gyimóthy, S. \& Mykletun, R. (2009). Scary food: Commodifying culinary heritage as meal adventures in tourism. Journal of Vacation Marketing, 15 (3), 259-273. doi: 10.1177/1356766709104271

Hoefle, S. W. (2016). Multi-functionality, juxtaposition and conflict in the Central Amazon: Will tourism contribute to rural livelihoods and save the rainforest? Journal of Rural Studies, 44, 24-36. doi: 10.1016/j.jurstud.2015.12.009

Hsieh, H-F. \& Shannon, S. E. (2005). Three approaches to qualitative content analysis. Qualitative Health Research, 15 (9), 1277-1288. doi: 10.1177/1049732305276687

Montanari, A. \& Staniscia, B. (2009). Culinary tourism as a tool for regional re-equilibrium. European Planning Studies, 10 (17), 1463-1483. doi: 10.1080/09654310903141656

Muchnik, J. (2012). Sistemas agroalimentarios localizados: Desarrollo conceptual y diversidad de situaciones. In G. Torres \& R. Larroa (Eds.) Sistemas agroalimentarios localizados. Identidad territorial, construcción del capital social e instituciones (pp.25-42). México: UNAM, CIICH, FCPyS y Juan Pablos Editor.

Noy, C. (2008). Sampling knowledge: The hermeneutics of snowball sampling in qualitative research. International Journal of Social Research Methodology, 11 (4), 327-344. doi: 10.1080/13645570701401305

Piñuel, J. L. (2002). Epistemología, metodología y técnicas del análisis de contenido. Estudios de Sociolingüistica, 3 (1), 1-41.

Reig, E. (2002). La multifuncionalidad del mundo rural. Globalización y Mundo Rural, 803, 33-44.

Renard, M-C. \& Thomé-Ortiz, H. (2010). La Ruta de la Sal Prehispánica. Patrimonio alimentario, cultural y turismo rural en Zapotitlán de las Salinas, Puebla, México. Parma: European Association of Agricultural Economists.

Renard, M-C. \& Thomé-Ortiz, H. (2016). Cultural heritage and food identity: The pre-Hispanic salt of Zapotitlán Salinas, Mexico. Culture and History Digital Journal, 5 (1), 1-13.

Ron, A. S. \& Timothy, D. J. (2013). Understanding heritage cuisines and tourism: Identity, image, authenticity and change. Journal of Heritage Tourism, 8 (2-3), 99-104. doi: 10.1080/1743873X.2013.767818

Rytkönen, P., Bonow, M., Johansson, M., \& Persson, Y. (2013). Goat cheese production in Sweden - a pioneering experience in the re-emergence of local food. Acta Agriculturae Scandinavica, Section $B$ - Soil \& Plant Science, 63 (1), 38-46. doi: 10.1080/09064710.2013.798682

Rytkönen, P. (2016). Local resources, foreign influences, value creation, tradition and modernity. The case of a local Agro-food System in Jämtland, Sweden. Culture \& History Digital Journal, 5 (1), 1-13. doi: $10.3989 /$ chdj.2016.009

Sedesol. Secretaría de Desarrollo Social. (2008). Municipios con muy alta y alta marginación: Programa para el desarrollo local de microrregiones. México: SEDESOL.

Sepúlveda, M. (2006). Tequitlato de Zapotitlán. Dimensión Antropológica, 37, 49-85.

Stake, R. E. (2000). Case Studies. In N. K. Denzin \& Y. S. Lincoln (Eds.) Handbook of qualitative research (pp.134-164) London: Sage Publications.

Thomé-Ortiz, H. (2012). Un grano de sal: Aportaciones del turismo agroalimentario al desarrollo rural. El caso de la sal prehispánica de Zapotitlán Salinas, Puebla, México. (Tese de doutoramento não publicada). Universidad Autónoma Chapingo, México.

Thomé-Ortiz, H., Renard, M-C., Nava, C. \& De Souza, A. (2014). La Ruta del Nopal (Oppuntia spp). Turismo y Restructuración productiva en el suelo rural de la Ciudad de México. Rosa Dos Ventos, 6 (3), 390408.

UNWTO (United Nations World Tourism Organization) (2012). Global Report on food Tourism: Volume 4. Madrid: UNWTO.

Voth, A. (2010) Productos típicos regionales como recurso patrimonial y atractivo turístico: Sidra y desarrollo regional en Asturias. Actas do XII Colóquio Ibérico de Geografía, 6-9 outubro 2010. Faculdade de Letras (Universidade do Porto), Porto.

Williams, E. (2003). La sal de la tierra. México: El Colegio de Michoacán.

HUMBERTO THOMÉ-ORTIZ es Doctor en Ciencias Agrarias por la Universidad Autónoma Chapingo, México. Profesor Investigador del Instituto de Ciencias Agropecuarias y Rurales de la Universidad Autónoma del Estado de México. Especialista en Turismo Agroalimentario y presidente de la Fundación Mexicana de Turismo Rural. Ha desarrollado diversas investigaciones en zonas rurales de México, Brasil y la Polinesia Chilena. Actualmente, es responsable del proyecto de investigación: "Evaluación de la Dimensión Recreativa del Hongos Comestibles Silvestres, su interés socioeconómico y sus perspectivas 
de desarrollo rural". Financiado por el Consejo Nacional de Ciencia Y Tecnología. Es Miembro del Sistema Nacional de Investigadores. Entre sus distinciones se encuentra el Premio Nacional Arturo Fragoso Urbina, máximo galardón otorgado en el Área de la Ciencias Agrícolas. Endereço institucional: Instituto de Ciencias Agropecuarias y Rurales. Universidad Autónoma del Estado de México. El Cerrillo Piedras Blancas. Toluca, Estado de México. C.P. 50090.

MARIE CHRISTINE RENARD HUBERT es Doctora en Estudios Rurales-Sociología por la Universidad de Toulouse Le Mirail, Francia. Profesora - Investigadora del Departamento de Sociología Rural de la Universidad Autónoma Chapingo. Es Miembro del Sistema Nacional de Investigadores Nivel III. Especialista en Café y comercio Justo. Forma parte de la Red Nacional Sobre Sistemas Agroalimentarios de México. Su contribución científica, a través de sus publicaciones rebasa 1000 citas. Ha publicado en revistas como el Journal of Rural Studies y Sociología Ruralis. Endereço institucional: Departamento de Sociología Rural. Universidad Autónoma Chapingo, México. Carretera México-Texcoco, km. 38,5. C.P. 56230.

DANIEL DE JESÚS-CONTRERAS es Maestro en Agroindustria Rural, Desarrollo Territorial y Turismo Agroalimentario (ICAR-UAEMex). Actualmente, cursa el Doctorado en Ciencias Agropecuarias y Recursos Naturales, en el que desarrolla una investigación sobre la apropiación de alimentos con identidad territorial como recursos turísticos en la región vitivinícola de Querétaro, México. Su línea de investigación se centra en la Valorización Turística del Patrimonio Agroalimentario y sus diversas implicaciones socioculturales y territoriales. Endereço institucional: Instituto de Ciencias Agropecuarias y Rurales. Universidad Autónoma del Estado de México. El Cerrillo Piedras Blancas. Toluca, Estado de México. C.P. 50090.

Submetido em 15 setembro 2016

Aceite em 29 março 2017 